\title{
AN EFFICIENT APPROACH TO SHALLOW HIGH-RESOLUTION SEISMIC DATA ACQUISITION: PRELIMINARY RESULTS
}

\author{
Michiel van der Veen, Frank Lehmann, Peter Wild and Alan Green \\ ETH-Swiss Federal Instiute of Technology, Institute of Geophysics, ETH-Hönggerberg, \\ CH-8093, Zürich, Switzerland, email: michiel@augias.ig.erdw.ethz.ch
}

\begin{abstract}
INTRODUCTION
High-resolution reflection seismic techniques are powerful tools for mapping shallow geological structures (Steeples and Miller, 1990; Lanz et al., 1996). During the past decade, the quality of seismic data has improved significantly. This improvement can be ascribed to a better understanding of shallow seismic techniques and significant developments in technology. These advances not only have improved the data quality and increased the ability to record very high-fold data, but they also have increased significantly the logistical complexity of a typical shallow seismic survey; many more geophones now have to be planted and higher shot densities are required.

In light of this, the ETH-Zürich has initiated a project to increase the efficiency of highresolution seismic profiling techniques, with the principal goal to markedly decrease the effort, field time and costs of shallow surveys. As an initial step in this direction, we report here the preliminary results of employing a new towed land streamer for high-resolution seismic applications.
\end{abstract}

\section{TOWED LAND STREAMER}

Accurate determination of geophone and shot locations and the planting of large numbers of "standard" spiked geophones are time consuming and costly aspects of seismic data acquisition. To increase efficiency, the concept of a snow streamer, which has successfully been employed in snow covered areas (Eiken, 1989), is being adapted for solid land applications. A multiple 96-channel seismic cable has been specially designed and is in the process of being manufactured for this purpose. It will consist of 96 takeouts at 1-meter intervals. The seismic cable, or land streamer (Fig. 1), is to be pulled by an all terrain vehicle. A kevlar outer casing, that increases the strength of the cable will help prevent the cable from being damaged as it is pulled across rugged ground.

For mobility reasons, the land streamer will be divided into interchangeable segments, each with 12 takeouts. The individual segments will be connected to each other via waterproof marine connectors. The takeouts can be connected to either standard spike geophones or to selfrotating gimbal geophones. Gimbal geophones, originally designed for use in swamp areas, have the advantage that they don't have to be "planted".

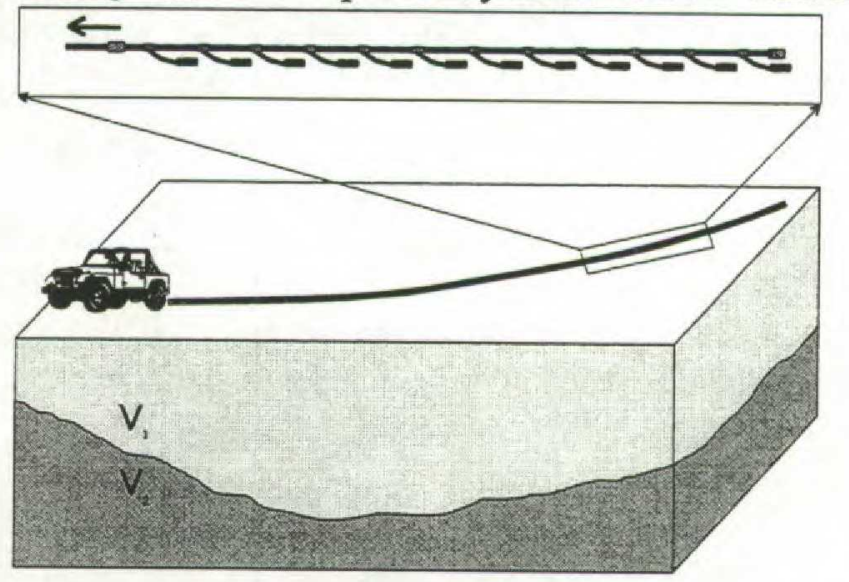

Figure 1: Schematic illustration of a land streamer to be pulled by an all-terrain vehicle. The land streamer comprises segments, each with 12 gimballed geophones. 


\section{TESTS OF GEOPHONE TO GROUND COUPLING}

A critical issue in the innovative land streamer concept is the geophone-ground coupling. Gimbal geophones have the potential to record high-quality data only when the seismic wave field can be recorded with minimal distortion in the frequency range of interest. (up to 500 $\mathrm{Hz}$ ). Various coupling experiments have been performed to test the quality of the recorded wave field. At a test site in Zürich (Switzerland), $30 \mathrm{~Hz}$ spike geophones were planted alongside 6 gimbal units with identical $30 \mathrm{~Hz}$ velocity sensors. Two typical results from these experiments are shown in Figures 2 and 3. In Figure 2, the response of a $30 \mathrm{~Hz}$ standard geophone is compared with the response of a $30 \mathrm{~Hz}$ gimbal geophone that is poorly "planted" alongside the standard geophone. There are major phase and amplitude differences between the responses. In contrast, Figure 3 shows the results when the gimbal geophone is planted in a small ditch. Phase and amplitude changes have been significantly reduced. Note that minor differences in geophone response may be due to very local variations in near-surface conditions and differences in electro-mechanical characteristics of the individual sensors, but these are likely to be small compared to the effect of ground coupling.
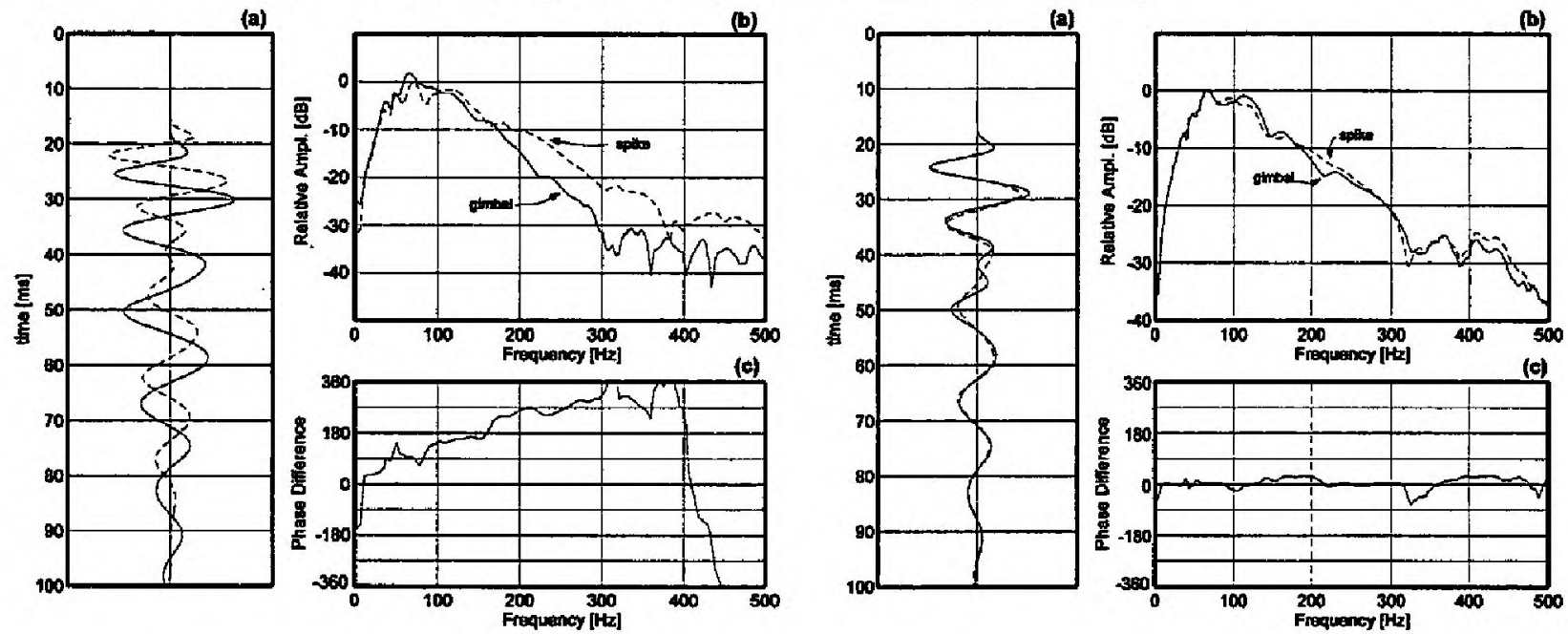

Figure 2: Results of ground coupling comparisons between $30 \mathrm{~Hz}$ spiked (dashed line) and poorly planted

Figure 3: Equivalent to Figure 2, but with the gimbal $30 \mathrm{~Hz}$ gimballed geophones (solid line). (a) shows typical recorded traces. (b) displays the equivalent amplitude spectrum of the two traces. (c) shows the phase difference between the responses of the two geophones

The positive results of the coupling experiments show that gimballed geophones have the potential to record high-resolution seismic data if they are in good contact with the ground. This contact can be achieved by housing the sensor in a heavy robust outer shell with a smooth surface and by laying the geophone in a small ditch.

\section{FIELD EXAMPLE}

In order to compare data recorded with gimbal geophones with those recorded with "standard" geophones, two short coincident seismic reflection profiles have been recorded in the Reuss delta, central Switzerland. The geology in the Reuss delta is dominated by braided river deposits, overlying lacustrine sands and clay. The ground water table is at $\sim 0.7$ to $\sim 3$ meters. Two nominal 18 -fold reflection surveys have been simulated with 6 spike and 6 gimbal test geophones. Detailed recording parameters are given in Table 1. 
Figure $4 \mathrm{a}$ shows a typical shot gather recorded with standard $30 \mathrm{~Hz}$ geophones. Figure $4 \mathrm{~b}$ shows a shot gather recorded at the same location, with the gimbal units. The shot records are practically indistinguishable.

The two data sets have been processed with the same parameters. Processing included trace editing, first break top mute, air blast attenuation, time-variant spectral whitening, CMP-sort, velocity analysis, NMO correction, stack, and display with an AGC (100 msec).

As for the shot gathers, the spike- and gimbal geophone sections match very well (Figure 5). On the basis of information from a bore hole, approximately $2 \mathrm{~km}$ of the seismic survey, the first strong reflector $(200-250 \mathrm{msec})$ is interpreted as the boundary between outwash gravel deposits and fine sands. The basement is interpreted as the strong reflection at approximately $500-600 \mathrm{msec}$.

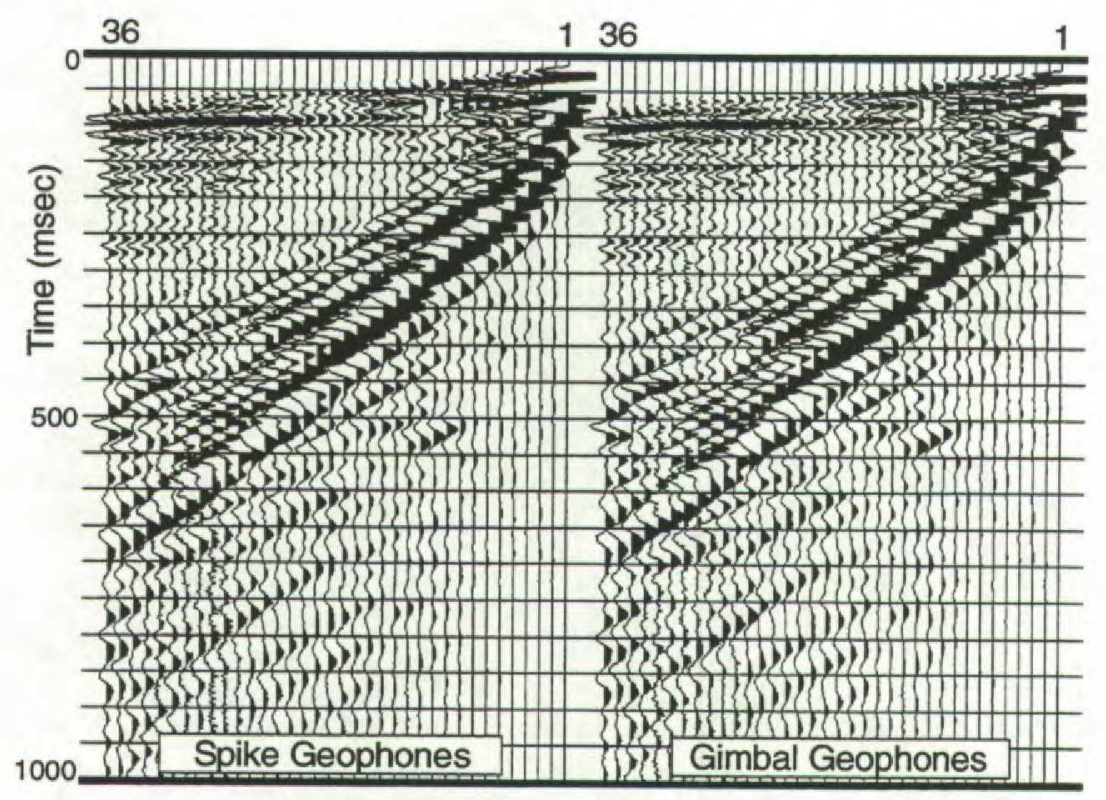

Figure 4: Two typical shot gathers recorded in the Reuss delta. The left record was recorded with "standard" spike geophones and the right one with gimbal geophones. The raw data have been scaled with a single individual scaling factor for each trace.
Table 1: Recording parameters for a high resolution seismic reflection profile in the Reuss Delta

\begin{tabular}{|l|l|}
\hline Source type & Shot gun \\
\hline Source offset & $2 \mathrm{~m}$ \\
\hline Receiver spacing & $2 \mathrm{~m}$ \\
\hline \# geophones & $2 \times 6$ \\
\hline Geophone type & $30 \mathrm{~Hz}$, spike/gimbal \\
\hline Sample rate & $0.250 \mathrm{msec}$ \\
\hline Nominal fold & 18 \\
\hline Total length & $210 \mathrm{~m}$ \\
\hline
\end{tabular}




\section{ACKNOWLEDGEMENTS}

We grateful acknowledge the valuable discussions with Heinrich Horstmeyer (ETH) and Pete Maxwell (SENSOR Nederland bv), and the technical support of Christoph Barlöcher (ETH). The seismic data has been recorded with a 120-channel BISON Jupiter acquisition system. This research is funded by the Jubilee Fund of the ETH-Zürich.

\section{REFERENCES}

Eiken, O., Degutsch, M., Riste, P. and Rod, K., 1989, Snowstreamer: an efficient tool in seismic acquisition: First Break, 7, 374-378

Lanz, E., Pugin, A., Green, A.G. and Horstmeyer, H., 1996, Results of 2- and 3-D highresolution seismic reflection surveying of surficial sediments: Geophysical Research Letters, 23, 491-494

Steeples, D.W., and Miller, R.D., 1990, Seismic reflection methods applied to engineering, environmental and groundwater problems: Geotechnical and Environmental Geophysics v. I, edited by S. Ward, Soc. Expl. Geophys., Tulsa, Oklahoma, 1-30

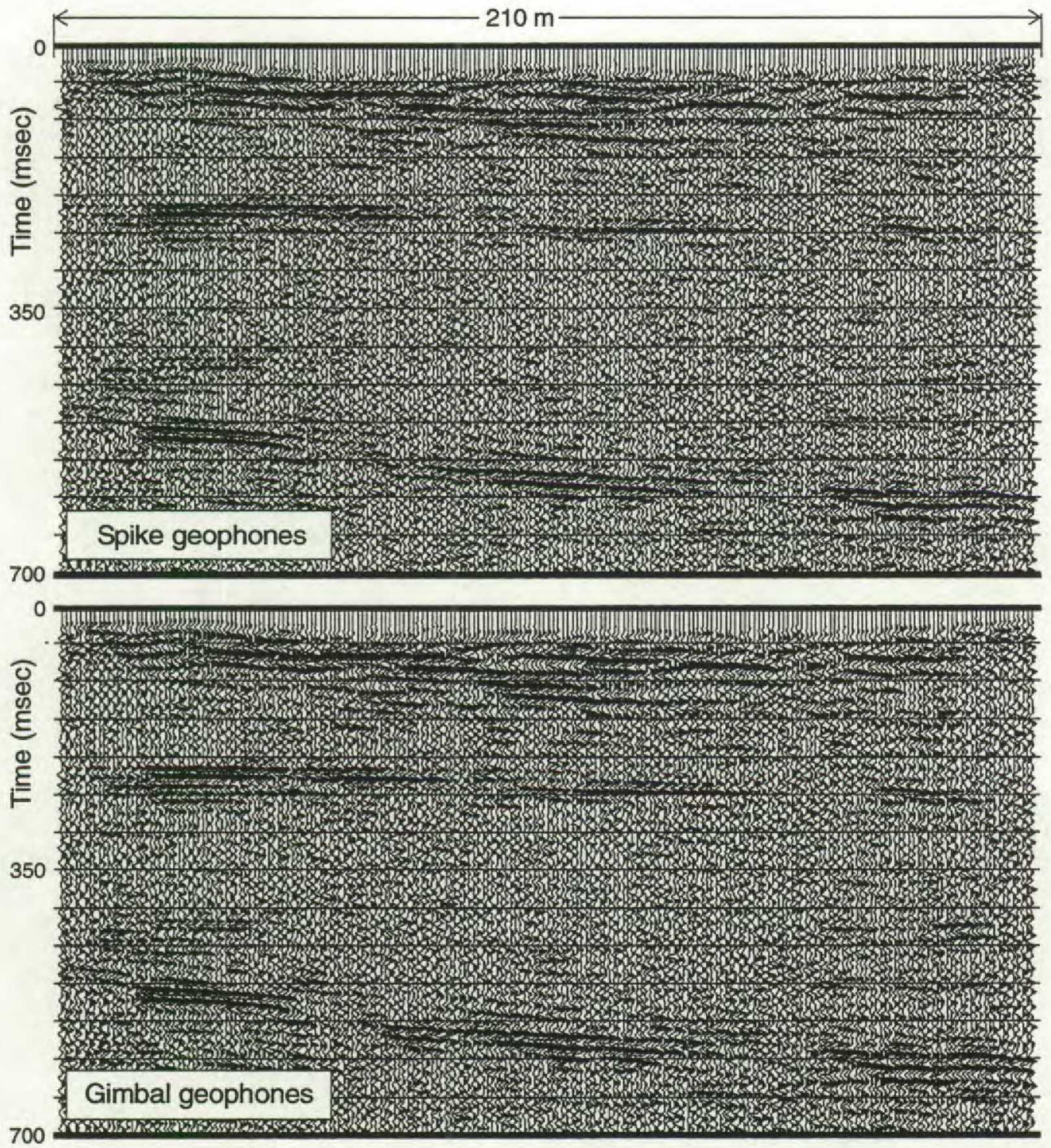

Figure 5: Two seismic reflection data sets, recorded simultaneously at the same location. The top section was recorded with standard spike geophones, whereas the bottom section was recorded with gimbal geophones. 